\title{
Questões sobre Arte Brasileira nas bienais do Mercosul
}

\section{BIANCA KNAAK}

\section{Resumo}

Este artigo identifica os modos de apresentação e distinção da produção artística brasileira durante as Bienais do Mercosul frente a ambivalência dos discursos curatoriais, especialmente sobre a globalização e internacionalização da arte contemporânea em circuitos regionais. Olhando para as produções nacionais de destaque ao longo dos anos, identifica o reaparecimento de artistas e também examina o papel das homenagens a cada edição.

Palavras-chave:

Curadoria, Arte Brasileira, Bienal do Mercosul 


\title{
Issues about Brazilian Art in the Mercosur biennials
}

\author{
BIANCA KNAAK
}

\section{Abstract}

This paper identifies the modes of presentation and the distinction of the Brazilian artistic production throughout the Mercosul Biennials on face of the ambivalence of curatorial discourses, especially on globalization and internationalization of contemporary art in regional circuits.

Keywords: Curator, Brazilian Art, Mercosul Biennial Looking for the national productions highlighted over the years; identifies the of artists reappearance and also examines the role of tributes to each edition. 
Na Bienal de Artes Visuais do Mercosul os modos de apresentação e distinção da produção artística brasileira, com notáveis variações/ reavaliações a cada edição, incluem a tarefa de entender o esforço localizado para a articulação internacional da produção artística contemporânea regional (central para os seus pares e periférica em relação aos seus modelos) numa era de fluxos, câmbios e impermanências de riquezas, culturas e identidades.

Seguindo um modelo de exposição bastante ajustado a realidade brasileira do sul do país, embora seja ainda jovem no roteiro das bienais internacionais, a mostra em Porto Alegre já se notabilizou entre os gestores culturais brasileiros, tanto por seus procedimentos administrativos quanto por suas investidas curatoriais. Seu modus operandis é afinado e pró-ativo, diria mesmo afirmativo, para uma produção regional de interesse artístico global. Nota desse reconhecimento é a participação de Justo Werlang - um dos fundadores e mais atuantes dirigentes da Fundação Bienal do Mercosul - na diretoria da $29^{\text {a }}$ Bienal de São Paulo (BSP) aliada a promessa do presidente da Fundação BSP de promover um "olhar para a arte contemporânea a partir de uma ótica brasileira" (MARTINS, 2009). Werlang, referindo-se à $1^{\text {a }}$ Bienal de Artes Visuais do Mercosul, que pretendia reescrever a história da arte sob a perspectiva "não euro-norte-americana", logo identificou essa promessa "com o que se fazia em Porto Alegre" (apud MARTÍ, 2009).

Apesar da intenção política dessa ótica brasileira aproximando as bienais de São Paulo e do Mercosul - e, embora em ambas, a organização unificada da cultura artística regional reunida nas bienais seja um recurso espetacular de visibilidade, análogo às necessidades econômicas promocionais no mercado internacional - as curadorias de cada uma (ainda que se repitam ou alternem) seguem jogando, driblando e 
reinventando distintamente as teses de independência cultural para a promoção da arte brasileira. Defendem que a globalização e as trocas culturais que lhes são peculiares não representam a homogeneização total dos bens culturais e nem a completa mercantilização da arte. Antes, tensionam o campo artístico em suas instâncias de visibilidade e estratégias de distinção social com suas tendências comerciais.

Explicitamente, no entanto, a promoção identitária territorializada não parece ser a tônica dos critérios seletivos das curadorias propostas em bienais. Em boa medida a análise dessas curadorias - como de resto de todas as grandes exposições - nos encaminha para um registro subjetivo e "fundamentalmente tautológico do espetáculo", decorrente, "do simples fato de seus meios serem, ao mesmo tempo, seu fim" (DEBORD, 1997, p.17). No entanto, segundo os entusiastas do modelo bienal, "a velocidade das transformações da arte contemporânea só pode ser atualizada pelas bienais. É nelas que o corpo mais amplo da produção atual encontra um meio de veiculação" (FIDÉLIS, 2005, p.136).

Dessa forma, e considerando as circunstâncias esterilizantes do espetáculo, lamenta-se, como aponta Stéphane Huchet, a falta de "condições de visibilidade cognitiva e pública da arte brasileira a partir da situação de sua historiografia" (2008, p.49), sobretudo porque a forma de "mediação principal que as exposições realizam tanto no país quanto no exterior" é insuficiente e fragmentária. Contudo, nas análises que circulam, acompanhando as exposições, sobretudo nos catálogos, destaca-se:

a questão da relação e da geopolítica dos intercâmbios entre o Brasil e outros centros, uma re-escritura da história global da arte parecendo encontrar hoje contexto mais favorável, mas ainda não concretizado (HUCHET, 20o8, p.49).

Por outro lado, nesse "contexto mais favorável" os efeitos da globalização na apresentação e recepção das artes visuais na maioria das vezes apenas ampliam os procedimentos de musealização já iniciados no século XIX. Ao deslocar as obras de diversas épocas e territórios para um mesmo espaço fruitivo e de conhecimento atemporal, da mesma forma que o museu, "a tecnologia global da informação desespacializa o acesso às obras, 'desligando' literalmente a distância e a diferença dos lugares” (KUDIELKA, 2003, p. 136). Pouco importará, sob essa lógica promocional e de acessibilidade universal, 
a origem das produções e a subjetividade materializada em poéticas/poiéticas. Quer seja arte made in Brasil, Mercosul ou Estambul, pouco saberemos sobre a constituição de seus sistemas simbólicos pois, o modo de conceber e legitimar o circuito de exposições internacionais quase não permite vencer cognitivamente "as grandes distâncias do planeta: antes, subtrai-se cabalmente a informação ao seu contexto no mundo" (KUDIELKA, 2003, p. 136). Não obstante, extrapolando seus limites territoriais, as Bienais do Mercosul vem se consolidando enquanto plataforma de afirmações transversais e propositivas desse contexto global "mais favorável" e, como veremos, já concretizado.

\section{Desdobramentos contínuos}

Para ultrapassar os recorrentes enfoques sobre identidade e geopolítica que vicejam na cultura visual contemporânea, em 2011 a Bienal renova a investigação dos significados que podem fundar ou coabitar territórios. A 8a edição vem desdobrando, publicamente, o tema da territorialidade em "Ensaios de geopoética", que serve de título para mostra. Tanto quanto em edições anteriores, a proposta é de uma mega exposição fluindo, física e conceitualmente, em muitos (e talvez insuspeitos) lugares da capital e do interior do Rio Grande do Sul, revisitando algumas estratégias de expansão e inclusão já implementadas pelas edições anteriores da própria Bienal do Mercosul ${ }^{2}$.

A história surge das contradições entre mundo e lugar, costumava dizer o geógrafo Milton Santos, citado na primeira edição da Bienal do Mercosul. Desde então, cartografar a produção artística latino-americana para além da geografia topográfica é um exercício permanente da Bienal do Mercosul. Vislumbrando a fluência das trocas culturais, por meio dos trânsitos, trâmites e transações comerciais que sugerem os acordos multilaterais em prol de uma economia regional, a Bienal sempre extrapolou os limites do Mercosul. Tanto na seleção de artistas quanto na definição dos curadores convidados. Essa foi uma maneira encontrada para alicerçar a promoção internacional da arte na e da América Latina em um universo extremamente competitivo, onde territórios são bens ao mesmo tempo simbólicos e produtivos. Nessa perspectiva nos interessa acompanhar como a produção brasileira vem sendo apresentada no conjunto das Bienais do Mercosul. Afinal, a $\mathbf{1}^{\mathrm{a}}$ - Bienal do Mercosul queria, nas palavras de seu curador (Frederico Morais), reescrever a história da arte. 


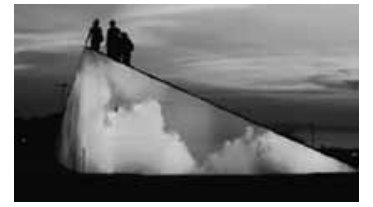

Figura 1

Sem negar o legado artístico ocidental, a edição inaugural reivindicava legitimidade e autonomia intelectual para (re) interpretá-lo e ampliá-lo com a produção latino-americana. Na seqüência, nas edições de 1999 e 2001, sob interpretações de identidade e contemporaneidade os curadores (Fabio Magalhães e Leonor Amarante) questionavam a compleição de um espaço do regional em um mundo globalizado. E, em 2003, ao duvidar da linearidade da história, a $4^{\underline{a}}$ Bienal confirmava, segundo o curador geral (Nelson Aguilar), que a arte toma o elã de tempos e lugares diversos. Nesta mesma edição, é importante lembrar, ocorreu a Mostra Transversal, com vários artistas não-latino-americanos curados pelo alemão Alfons Hug. Com esta mostra quase paralela e ao mesmo tempo integrando a curadoria principal, era ainda mais evidente a polissemia do mundo ocidentalizado, matizado por influências incontornáveis para a compreensão da produção artística recente.

\section{Desterritorializar e internacionalizar}

Quando a $5^{\mathrm{a}}$ Bienal organizou um novo resgate histórico e prospectivo da arte na América Latina, assim como na $1^{\underline{a}}$ edição, o curador (Paulo Sérgio Duarte) espalhou exposições por inúmeros espaços na cidade, trouxe muitos artistas brasileiros e promoveu um balanço da cena artística regional, agora em diálogo com a produção internacional. Fez ainda a mostra Fronteiras da Linguagem (com quatro artistas nascidos bem longe da América Latina) onde buscou sobrepor as fronteiras políticas e geográficas para configurar a internacionalização definitiva da Bienal do Mercosul.

Em 2007, na edição seguinte, foram apresentados artistas de quatro continentes. Destes, sob leituras transversais exibiram-se obras que se desprendiam de seus territórios pátrios para se perfilarem em sensibilidade estética e construção artística hors sol. Para o curador (Gabriel Pérez-Barreiro) as concepções e relativizações de fronteiras e territórios para a arte foram estendidas e radicalizadas e a abertura internacional se confirmava já irreversível. A partir de então, perfilada aos principais eventos do gênero, a Bienal se apresenta como plataforma regional de afirmação e inserção artística internacional.

\section{Brasileiros destacados}

Seguindo sua vocação promocional afirmativa destacamos que, até a $7^{\mathrm{a}}$ edição da Bienal do Mercosul, apenas seis ar- 
tistas brasileiros tiveram participação em três edições. Ninguém participou mais do que Cildo Meireles, Félix Bressan, Laura Vinci, Maria Leontina, Milton Dacosta e Waltércio Caldas. Note-se ainda que, destes, apenas Milton Dacosta e Laura Vinci não haviam participado da curadoria de Frederico Morais. Assim, considerando que dois haviam morrido na década anterior a $1^{\mathrm{a}}$ Bienal (Dacosta e Leontina), e que Cildo e Waltércio, quando participaram da $1^{\underline{a}}$ Bienal do Mercosul já eram nomes importantes (com participações nas Bienais de São Paulo, Veneza e Kassel), entre as recorrências encontraremos apenas dois artistas que poderiam ser considerados emergentes e, portanto, uma aposta para o futuro da arte brasileira internacional: Félix Bressan (presente já na $1^{\underline{a}}$ edição) e Laura Vinci (a partir da $2^{\underline{a}}$ edição)3. Para detalhar esse levantamento percorreremos, a seguir, as justificativas curatoriais para a seleção brasileira, destacada em cada edição.

\section{Matriz fecunda}

Na montagem da $1^{\mathbf{a}}$ Bienal do Mercosul o curador organizou as obras em três vertentes criativas/ propositivas: Política a arte e seu contexto; Construtiva - a arte e suas estruturas; e Cartográfica - território e história. Além destas vertentes ${ }^{4}$, o segmento intitulado Último Lustro reunia obras realizadas entre 1995 e 1997 por artistas emergentes, dentre os quais 15 brasileiros ${ }^{5}$. Portanto, mesmo audaciosa, a $1^{\underline{a}}$ Bienal do Mercosul foi também pouco prospectiva pois a produção recente teve poucos expoentes (sobretudo quando comparada às edições posteriores). No conjunto de 210 artistas, 50 eram brasileiros, mas apenas 15 estavam entre os chamados "jovens".

O olhar autônomo e independente dos ditames do mercado internacional solicitado aos curadores estrangeiros era, obviamente, pretendido também para a seleção brasileira. Mas, aparentemente sem alternativas, Frederico Morais mostrou uma produção globalizada repercutindo a produção dos grandes centros internacionais. Dizia que, "na arte brasileira dos anos 90, na criatividade plástica do último lustro do século XX, não existem mais fronteiras (...)”. Segundo ele, "o que temos, hoje, são re-criações, re-composições, re-leituras, re-apropriações e re-ready-mades" (1997b, p.159). Noutras palavras, ironicamente exibia-se o alinhamento da produção recente com a arte promovida nos centros euronorte-americanos.

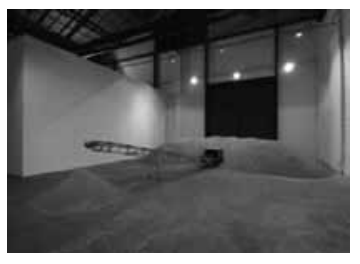

Figura 2

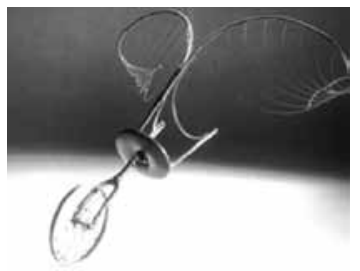

Figura 3 
Àquela altura, os parâmetros do curador já eram indicação judicativa de um campo que seguiria se organizando noutra plataforma de afirmação. Onde, mais do que a internacionalização de um circuito regional, em eventos tais, a visibilidade internacional mostra-se um alvo que progressivamente minimiza iniciativas artísticas de resistência estética, conceitual, política.

Na $1^{\text {a }}$ Bienal do Mercosul os brasileiros destacados também não estavam constituídos pelo sistema segundo um programa estético contra-hegemônico, propriamente dito. Pelo contrário, a maioria deles já exibia em seu currículo trajetórias institucionais. Do universo composto por 50 nomes, selecionados para uma apresentação histórica, ao longo de catorze anos, 28 tiveram suas produções reivindicadas para participar também de outras edições da própria Bienal do Mercosul.

Com esses dados percebemos que a curadoria de Frederico Morais não foi apenas pioneira de um projeto potencialmente revelador, descentralizado (uma bienal em Porto Alegre). Foi também inaugural, no contexto regional globalizado (MERCOSUL), de uma visão curatorial legitimadora que constrói tradições/trajetórias nacionais com os artistas sendo exibidos e legitimados simultaneamente nacional e internacionalmente.

\section{Homenagens estratégicas}

Sempre muito valorizadas pelos curadores gerais, as homenagens foram suspensas na $6^{\underline{a}}$ e $7^{\underline{a}}$ edições, e só retornaram à Bienal do Mercosul na 8a edição, em 2011. Entendidas enquanto recurso promocional, não será exagero dizer que as homenagens também podem servir como berlinda internacional, tanto dos artistas quanto de suas origens geográficas. Por isso, os homenageados de cada Bienal também inspiram reflexão sobre a apresentação internacional de valores artísticos brasileiros em searas geopolíticas. Para tanto será fundamental notar que dos seis artistas homenageados, quatro eram brasileiros, três dos quais nascidos no Rio Grande do Sul.

No projeto da $1^{a}$ edição a intenção era homenagear o uruguaio Pedro Figari (1861 -1938) que fora sucesso na $23^{\underline{a}}$ Bienal de São Paulo (1996) e que, segundo Morais, foi um "pintor, ensaísta, poeta, jurista e educador, defensor de uma política americanista e teórico do regionalismo crítico" (MORAIS, 1997, p.o6). Não obstante, dificuldades operacionais resultaram na homenagem ao artista argentino Xul Solar (1887-1963) e ao crítico de arte brasileiro Mário Pedrosa (1901-1981). Nas 
quatro edições seguintes, nenhum outro teórico foi homenageado e apenas artistas brasileiros receberam a honraria.

$\mathrm{Na} 2^{2}$ edição exibia-se a mostra paralela "Picasso, Cubismo e América Latina" que buscava reciprocidades entre artistas europeus e latino-americanos e, apropriadamente, com uma grande mostra retrospectiva o homenageado foi Iberê Camargo (1919-1994). O curador Fábio Magalhães afirmava - talvez respondendo a Frederico Morais que não encontrou espaço para Iberê em sua curadoria - que o "corte proposto dentro da vanguarda histórica [atualizava] o discurso da contaminação, do sincrônico, da prospecção positiva sem retórica” (MAGALHÃES, 1999b, p.o9). Era, portanto, estratégico que Iberê, "uma das figuras de proa da arte brasileira deste século" (MAGALHÃES, 1999b, p.14) dividisse as dependências do Museu de Arte do Rio Grande do Sul com Picasso, Braque, Rivera e outros, permitindo aos visitantes clivagens inéditas.

A $2^{\underline{a}}$ e $3^{\underline{a}}$ edições, ambas curadas por Fábio Magalhães e Leonor Amarante, trouxeram 33 e 69 artistas brasileiros, respectivamente. Nelas, os curadores investiram nas questões da identidade e contemporaneidade frente às imbricações próprias de um contexto que globaliza o planeta economicamente. Dentre os 102 artistas brasileiros, somadas as duas curadorias de Magalhães e Amarante (a maior parte realmente jovens na cena contemporânea), 21 participaram uma segunda vez ao longo das sete edições da Bienal, mas apenas Marco Giannotti, Joel Pizzini e Félix Bressan participaram da $2^{\underline{a}}$ e da $3^{\underline{a}}$ edição.

$\mathrm{Na} 2^{\text {a }}$ Bienal do Mercosul, na "gramática multifacetada" da produção brasileira, Leonor Amarante destacava a pintura, a fotografia, as instalações e as novas mídias, em suportes e operações díspares, concentradas sob explorações alusivas a "conceitos de memória, esquecimento, contaminação e resistência"(AMARANTE, 1999, p. 45 e 46). Mas foi a edição seguinte que homenageou o videomaker Rafael França (19571991), expondo seus trabalhos em gravura, xerografia e vídeo. Apesar disso, na $3^{\text {a }}$ Bienal do Mercosul preconizava-se a pintura 6 "como expressão da contemporaneidade, e não como resistência fossilizada”(MAGALHÃES, 2001, p.15 e 16).

Sob a curadoria geral de Nelson Aguilar, em 2003 o artista homenageado foi Saint Clair Cemin (1945). Na 4- edição da Bienal do Mercosul a Arqueologia Contemporânea (título da mostra), começava com artefatos das culturas pré-colombinas e terminava com a doação à prefeitura de Porto Alegre de uma grande escultura de Cemin, feita em resina sintética. A tese dessa curadoria enfatizava desde a investigação genética da 


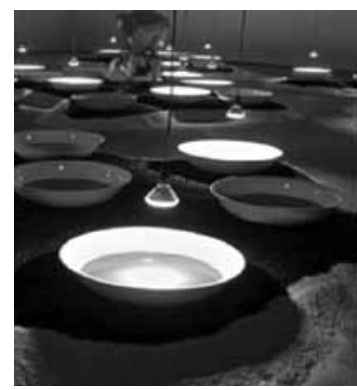

Figura 4

ascendência racial até as afiliações da arte contemporânea e, da forma como foi perpetuada, a doação da obra de Cemin tornava-se também uma homenagem de pretensão ontológica. Pois, segundo Aguilar, aquela "hipercuia", enunciaria "o modo cósmico de ser gaúcho" (AGUILAR, 2003, p.44).

Ainda nessa edição, procurando os "cânticos de origem" da nossa identidade ${ }^{7}$, o curador festejava a investigação genética da arte latino-americana num trabalho assinado por Ary Perez e Sergio Danilo Pena onde se revelava, ao perscrutar amostras de DNA de expoentes da própria Bienal do Mercosul, uma "fotografia gênica", produzindo "um mapa da ancestralidade genética" da arte e dos artistas sul-americanos (PEREZ apud AGUILAR, 2003, p.71). Nesse contexto, dentre os nove artistas da representação brasileira ${ }^{8}$, curada por Franklin Pedroso, destacava-se a obra de Lygia Pape: bacias brancas com líquidos coloridos sobre montes de arroz e feijão, teatralmente iluminados e espalhados no chão de uma grande área "representando testes de DNA (...) num belo ato poético" (PEDROSO, apud AGUILAR, 2003, p.271).

\section{Transbordamentos}

Como estratégia para constituição de um lastro artístico regional, entre a $2^{\mathrm{a}}$ e a $4^{\mathrm{a}}$ edições, as homenagens poderiam também reforçar o mérito local, qualificando Porto Alegre como pólo cultural, em evidente competição com o eixo RioSão Paulo9. Nessa abordagem, considerando que os curadores gerais, até então eram oriundos do centro do país, poderíamos supor cada homenagem como um movimento de apresentação e legitimação artística intramuros. Pois, quando homenageados, Iberê Camargo, Rafael França e Saint Clair Cemin (todos nascidos no Rio Grande do Sul), ainda não eram artistas suficientemente visitados pelos centros hegemônicos, alguns nem mesmo regionalmente. Assim, as homenagens de cada edição das Bienais do Mercosul serviriam, também, como oportunidade de projeção institucional.

Foi diferente, no entanto, o contexto curatorial que homenageou o mineiro Amilcar de Castro, em 2005. Homenagem que não pode ser enquadrada como estratégia de "lançamento" ${ }^{\prime \prime}$, obviamente. Na $5^{\underline{a}}$ Bienal do Mercosul ela sustentava uma abordagem da arte contemporânea brasileira a partir de suas matrizes construtivas. O homenageado era destaque na curadoria de uma nova revisão histórica, agora com interesse prospectivo. 
Sob a curadoria geral de Paulo Sergio Duarte a opção por expor Histórias do Espaço e do Tempo (título da mostra) permitiu um novo balanço da cena artística regional, porém em franco diálogo com a produção internacional. O curador e sua equipe organizaram a mostra em vetores temáticos: Da Escultura à Instalação; Direções no Novo Espaço (incluindo fotografia, cinema, vídeo, ciberarte e performance); A persistência da Pintura (onde Iberê Camargo esteve pela segunda vez numa Bienal do Mercosul) e Transformações do Espaço Público, com intervenções definitivas dos brasileiros José Resende, Mauro Fuke, Waltércio Caldas e Carmela Gross; além da já citada exposição Fronteiras da Linguagem. Enquanto projeto, a $5^{\mathrm{a}}$ Bienal foi a que mais se aproximou

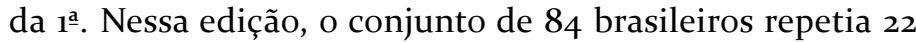
artistas da $\mathbf{1}^{\mathrm{a}}$ Bienal do Mercosul, inclusive o homenageado, Amilcar de Castro.

Depois da $5^{\mathrm{a}}$ edição, as duas edições imediatamente seguintes não utilizaram mais homenagens em suas construções curatoriais. Ambas com curadores gerais estrangeiros, tanto a 6. (intitulada "A terceira margem do rio"), quanto a $7^{\text {a }}$ edição ("Grito e escuta"), tiveram espaços, obras e museografia para isso e foram igualmente reveladoras e lisonjeiras com a produção dos brasileiros. Basta lembrar, por exemplo, na 6a edição, da exposição, de Öyvind Fahlström (1928-1976), nascido no Brasil e criado na Europa e, na $7^{\text {a }}$ Bienal do Mercosul " , das salas especiais de Paulo Bruscky (1949) e Cildo Meireles (1948).

Em 2011, volta o recurso da homenagem e, nessa $8^{a}$ edição, literalmente como um abre-alas curatorial. A obra do chileno Eugênio Dittborn (1943) é o destaque para abordagem do conceito chave da mostra - a territorialidade - em seu amplo espectro vivencial (transterritorialidade, desterritorialidade, deslocamentos e pertencimentos). Para explorar essa temática, tão recorrente na cena pós-moderna (e na própria Bienal do Mercosul), o curador promete orquestrar estratégias (coletivas ou individuais) de apresentação e constituição de territórios, tanto em suas aporias geográficas e geopolíticas quanto de seus processos simbólicos - sejam eles afetivos e mnemônicos ou geopoéticos. Assim, os trabalhos de Dittborn, especialmente suas Pinturas Aeropostais, estarão no Santander Cultural (no centro histórico de Porto Alegre) e, segundo o curador (José Roca), também visitarão diferentes lugares para ativar as potencialidades estéticas e artísticas de cada itinerário ${ }^{12}$.

Além da homenagem oficial, subliminarmente, o Rio Grande do Sul também está sendo homenageado na 8a Bienal 
do Mercosul. A historiadora da arte brasileira Aracy Amaral, convidada pelo curador geral, organiza em exposição uma visão crítica da paisagem regional. Nesta exposição, (intitulada "Além fronteiras") ela percorre o passado e o presente cultural da ponta sul do Brasil e suas fronteiras em busca de um inventário de influências estrangeiras e revelações locais que de alguma forma ajudaram a configurar e conceber a arte e a visualidade do Estado, além de revelar os modos de ver e viver os territórios do sul. Dentre nove artistas seleciona$\operatorname{dos}^{13}$, seis são brasileiros, quatro dos quais nascidos no Rio Grande do Sul e com participações em edições anteriores das Bienais do Mercosul ${ }^{14}$.

\section{Multilateralizando}

Não faremos aqui uma análise das obras citadas, nem mesmo leituras possíveis a partir das teses centrais dos curadores. Um trabalho assim exigiria outra abordagem metodológica, e obviamente, mais espaço. Por ora nos cabe destacar que as revelações de cada edição, seja com homenagens, retrospectivas ou estréias, podem contribuir para a construção crítica de um campo que ainda aprende a escrever sua história. Assim, as recorrências desencadeadas por esse tipo de evento pedem olhares mais diligentes, entre outros aspectos, sobre aquilo que poderíamos apontar como imbricações entre "mundo e lugar". Afinal, arte e política instigam curadores no mundo inteiro, mas a política das artes ainda precisa discussões territorializadas para a compreensão do sucesso da maior mostra de arte da América Latina (como se intitula a Bienal do Mercosul desde o início) e dos artistas brasileiros por ela destacados.

\section{Referências}

AGUILAR, Nelson (Org.) 4므 Bienal de Artes Visuais do Mercosul. Porto Alegre: Fundação Bienal de Artes Visuais do Mercosul, 2003.

AMARANTE, Leonor. Gramática Multifacetada. In: II Bienal de Artes Visuais do Mercosul: catálogo geral. Porto Alegre: FBAVM, 1999.

DEBORD. Guy. A sociedade do espetáculo. Rio de Janeiro: Contraponto, 1997.

DUARTE, Paulo Sérgio (Org.) Rosa dos Ventos: posições e direções na arte contemporânea. Porto Alegre: Fundação Bienal de Artes Visuais do Mercosul, 2005. 
FIDÉLIS, Gaudêncio. Uma história concisa da Bienal do Mercosul. Porto Alegre: Fundação Bienal do Mercosul, 2005.

HUCHET, Stéphane. Presença da arte brasileira: história e visibilidade internacional. Concinnitas, ano 9, v.1, n. 12, jul. 2008, p. 48-65.

KNAAK, Bianca. Os Brancos da Bienal. Jornal Zero Hora, Porto Alegre, 10 nov. 2001. Cultura, p. 07.

. As Bienais de Artes Visuais do Mercosul: utopias \& protagonismos em Porto Alegre, 1997 - 2003. 2008. 289 f. Tese (Doutorado em História) - Instituto de Filosofia e Ciências Humanas, Universidade Federal do Rio Grande do Sul, Porto Alegre, 2008.

À Deriva num copo de mar. Jornal Zero Hora, Porto Alegre, o2 de outubro de 2010, Cultura, p.04.

KUDIELKA, Robert. Arte do mundo ou arte de todo mundo? Do sentido e do não-sentido da globalização nas artes plásticas. Novos Estudos CEBRAP, São Paulo, n. 67, nov. 2003, p.131-142,.

MAGALHÂES, Fábio. Contemporaneidade, a marca da II Bienal. In: II Bienal de Artes Visuais do Mercosul: Catálogo Geral. Porto Alegre: FBAVM,1999a.

. Iberê, senhor de si próprio. In: II Bienal de Artes Visuais do Mercosul: Iberê Camargo. Porto Alegre: FBAVM, 1999b.

. III Bienal de Artes Visuais do Mercosul: Catálogo Geral. Porto Alegre: FBAVM, 2001.

MARTÍ, Silas. Bienal de São Paulo importa modelo gaúcho de gestão. In: Jornal Folha de São Paulo, São Paulo, 13 de julho de 2009. Disponível em: < http://www1.folha.uol.com.br/ fsp/ilustrad/fq13072009o8.htm > Acesso em: 14 de julho de 2009.

MARTINS, Heitor, apud ALZUGARAY, Paula. A Bienal depois do caos. Revista Isto é. Disponível em: < http://www.terra. com.br/istoe/edicoes/2068/imprime142591.htm > Acesso em: 16 de julho de 2009 .

MORAIS, Frederico. Reescrevendo a história da arte latino-americana. In: Catálogo Geral da I Bienal do Mercosul, Porto Alegre: FBAVM, 1997a.

. Arte brasileira: lo de afuera, lo de adentro. In: $\mathrm{Ca}$ tálogo Geral da I Bienal do Mercosul, Porto Alegre: FBAVM, 1997b.

In: Jornal Zero Hora, Porto Alegre, o5 de janeiro de 1997, Revista ZH, p. o6. 
1. Ver MORAIS, 1997, p. 12 - 20. É importante observar essa aproximação entre as duas maiores bienais de artes visuais do país para entender como o sistema promotor das artes no Brasil tem um modo hegemônico de se apresentar interna e internacionalmente. Notamos ainda uma série de recorrências e retro-influências decorrentes dessa aproximação, sobretudo quando Justo Werlang passou a integrar a nova diretoria da Bienal de São Paulo. Da curadoria ao projeto educativo, serão vários os nomes que começam a transitar com desenvoltura entre uma e outra Fundação Bienal.

2. Lembremos do ônibus Chromobus, do venezuelano Cruz-Diez, circulando na capital gaúcha na $1^{\mathrm{a}}$ edição; da ocupação dos já extintos armazéns do cais do porto, na $2^{\underline{a}}$; das performances no Hospital Psiquiátrico São Pedro e a invenção de uma Cidade de Contêineres na $3^{a}$; da Mostra Transversal, na $4^{a}$ Bienal; da participação recorde de gaúchos na edição seguinte e o mobiliário urbano na orla do Guaíba; da metáfora da terceira margem trazendo artistas de quatro continentes à 6a Bienal; da Rádio Visual e o caráter relacional da programação Pré-Bienal da $7^{\mathfrak{a}}$ edição.

3. Ambos são da mesma faixa etária e tem formação acadêmica em artes. Bressan vive e trabalha em Porto Alegre e Vinci em São Paulo.

4. Genealogia da arte na América Latina que, segundo Morais, estaria completa apenas com a "vertente fantástica" e dependeria da participação mexicana, que naquele momento não fez parte da mostra.

5. Divididos em duas montagens estavam Efraim Almeida, Eliane Prolik, Gilberto Vançan, José Damasceno, Niura Bellavinha, Félix Bressan, Keila Alaver, Lia Menna Barreto e Eduardo Kac, além de Fernando Limberger, Fernando Lucchesi, Jorge Barrão, Marcos Coelho Benjamin, Marcos Chaves e o chileno radicado brasileiro Patricio Farias, estes numa proposta de intervenção urbana, chamada "Imaginário Objetual" Nesta participaram também Mário Sagradini (UR), Monica Giron (AR) e Sydia Reyes (VE), todos convidados a percorrer o centro de Porto Alegre buscando novas idéias e inspirações. Cf. dados fornecidos pelo Núcleo de Documentação e Pesquisa da Fundação Bienal de Artes Visuais do Mercosul.

6. VER: KNAAK, 2001, p.o7.

7. Ver: AGUILAR, 2003, p.41.

8. Ivens Machado, Janaína Tschäpe, José Damasceno, Laércio Redondo, Laura Lima, Lia Menna Barreto, Lygia Pape, Rosana Paulino. Na Mostra Transversal curada por Alfons Hug ainda estavam os brasileiros Tato Taborda, Artur Barrio e Maurício Dias (Maurício Dias e Walter Riedweg).

9. Ver KNAAK, 2008, p 63.

10. Nem mesmo para Porto Alegre que, três anos antes recebera uma grande exposição de Amilcar de Castro, curada por Marcelo Ferraz, no Santander Cultural, acompanhada de uma mostra paralela, reunindo dez artistas nacionais, intitulada Tangenciando Amilcar e curada por Tadeu Chiarelli. Além disso, quando da primeira Bienal do Mercosul, Amilcar de Castro participou, com mais dez artistas, do vetor "parque das esculturas", que legou obras de todos os participantes à cidade de Porto Alegre.

11. A $7^{\underline{a}}$ edição inovou em sua curadoria, levada a termo por um conjunto de nove pessoas, liderados por Victoria Noorthoorn (Argentina) e Camilo Yáñez (Chile).

12. Amparados por um Programa Pedagógico, essas ativações pretendem incentivar a construção de um sentido comum e compartilhado da arte naquele lugar, cidade ou comunidade. Portanto, o processo envolvido não deixa de ser uma proposta relacional, ainda que diferente daquelas que 
marcaram a edição de 2009, junto a algumas comunidades. Além disso, a tarefa de ativação de potencialidades e construção compartilhada de sentido resume o projeto pedagógico da Bienal como um todo (work in process) e seu interesse de contrapartida social.

13. A saber: Cao Guimarães; Carlos Pasquetti; Carlos Vergara; Felipe Cohen; Gal Weinstein; Irene Kopelman; José Alejandro Restrepo; Lucia Koch e Marina Camargo.

14. Sendo que ao concluir esse artigo a 8 a edição da Bienal ainda não foi inaugurada, para contextualização da abordagem promovida nesse texto, considerei apenas os dados confirmados pela assessoria de imprensa da Fundação Bienal do Mercosul e pelos próprios curadores citados.

Recebido em: 31/03/2011

Aceito em: 14/05/2011

\section{BIANCA KNAAK}

bknaak@hotmail.com

É pesquisadora e professora do Instituto de Artes da Universidade Federal do Rio Grande do Sul (UFRGS). Doutora em História e Mestre em Artes Visuais pela mesma Universidade. Integra o Comitê Brasileiro de História da Arte (CBHA). Investiga a promoção da arte brasileira contemporânea através de curadorias, bienais e grandes exposições, projetos museológicos e outras estratégias de institucionalização. Curadora, crítica de arte e artista sazonal, entre 1999 e 2002 dirigiu o Instituto Estadual de Artes Visuais e o Museu de Arte Contemporânea do Rio Grande do Sul. Em 2005 organizou o livro A(propria)ação entr\&tantas: artistas reunidos (ISBN 8589576078) que em 2010 participou da 29ª Bienal de São Paulo no terreiro “Longe Daqui, Aqui Mesmo". 